\title{
Bacterial infections in Indian cirrhotic patients: a prospective study
}

\author{
Deepak C. Gopinath ${ }^{1}$, Bhat Rashmi ${ }^{1}$, Sivichan Sonia ${ }^{1}$, Sharon Mary Stanly ${ }^{1 *}$, \\ Shalumol Jose ${ }^{1}$, Ranjan Amit ${ }^{1}$, Nicole R. Pereira ${ }^{2}$
}

\begin{abstract}
${ }^{1}$ Department of Pharmacy Practice, Karavali College of Pharmacy, Mangalore, Karnataka, India
${ }^{2}$ Department of Pharmacology, Fr Muller Medical College, Mangalore, Karnataka, India
\end{abstract}

Received: 05 April 2021

Accepted: 04 May 2021

*Correspondence:

Dr. Sharon Mary Stanly,

Email: sharon.sms.stanly@gmail.com

Copyright: ( ) the author(s), publisher and licensee Medip Academy. This is an open-access article distributed under the terms of the Creative Commons Attribution Non-Commercial License, which permits unrestricted non-commercial use, distribution, and reproduction in any medium, provided the original work is properly cited.

\section{ABSTRACT}

Background: Bacterial infections (BI) are more prevalent in liver cirrhosis (LC), high among hospitalized patients. The aim of this study was to explore the epidemiological pattern of BI in hospitalized patients with LC, and identification the causative agents. Objective of the study was evaluation of therapeutic/empirical approaches for these infections.

Methods: Inputs from the body fluid analysis and culture reports were recorded. The Child Pugh score (CPS) was used to assess the severity of liver disease. Antibiotic treatment strategy was analysed, prescribed antibiotics were checked for contraindications using Lexicomp software.

Results: Of 60 enrolled patients, four had mixed infection and 55\% were culture positive. There was a male preponderance $(83.3 \%)$. BI was more frequent in those aged 51-60 years $(38.3 \%)$ and $>60$ years $(35 \%)$. Higher proportion of patients $(60 \%)$ belonged to class C of CPS followed by class B $(31.7 \%)$. The most common causative organisms identified were E. coli $(28.5 \%)$, K. pneumonia (14.2\%), Enterococcus spp (11.4\%) and less common were $K$. oxytoca, Coagulase-negative staphylococci, Staphylococcus aureus, gram-positive cocci, gram-negative cocci, $P$. aeruginosa, S. hemolyticus, $\beta$-hemolytic streptococcus spp. Majority of the subjects had spontaneous bacterial peritonitis $(36.7 \%)$ followed by urinary tract infection $(21 \%)$, lower respiratory tract infection $(18.3 \%)$, sepsis $(13.3 \%)$, cellulitis $(3.3 \%)$ and acute gastroenteritis $(1.7 \%)$. Cephalosporin $(61.7 \%)$, rifaximin $(51.7 \%)$, penicillin and $\beta$ lactamase inhibitors $(36.7 \%)$ were the common prescribed antimicrobials.

Conclusions: There is a positive association between the risk of BI and severity of liver damage.

Keywords: Bacterial infection, Child pugh score, Liver cirrhosis, Spontaneous bacterial peritonitis

\section{INTRODUCTION}

Compromised immune status, along with structural and hemodynamic abnormalities in the patients with liver cirrhosis increases the risk and make them highly vulnerable to bacterial infections (BI). ${ }^{1} \mathrm{BI}$ are more prevalent in liver cirrhosis; 4-5 times higher and severe than that of patients without cirrhosis, high among hospitalized patients $(25 \%-47 \%) .{ }^{2-4}$ Preveden has reported a prevalence of $\mathrm{BI}$ in cirrhotic patients to be $38.15 \% .^{5}$ It is one of the major causes for sepsis, systemic inflammation and organ failure; brain being the frequent target $(55.7 \%)$ followed by kidney $(15.1 \%)$; circulatory (17.6\%) and respiratory failure $(15.8 \%)$ further make it critical. ${ }^{6}$ CANONIC study has noted renal failure as the most frequent organ failure, brain damage being second in the list and the incidence of circulatory (16.8\%) and respiratory $(9.2 \%)$ failure in the list. ${ }^{7}$ High mortality at one month and at one year is 4 times higher in patients with cirrhosis.

With a rising global trend in infections in cirrhotic patients, increase in associated morbidity, mortality can be expected, which is preventable and controllable with meticulous management. Emergence of drug resistance which high globally (40\%) and highest in India (70\%), calls for early empirical antibiotic therapy. ${ }^{8}$ 
Cirrhosis is listed as the $10^{\text {th }}$ most common cause of death globally. In advanced cirrhosis, BI is more common and a major cause of mortality. In cirrhotic patients, once the infection develops, it causes further damage and leads to more severe complications such as septic shock, hepatic encephalopathy, chronic liver failure, multi-organ failure and finally death. Severity of cirrhosis and rate of survival are assessed using the Child Turcotte Pugh (CTP) introduced by Child, Turcotte and Pugh. It helps to predict the life expectancy in patients with cirrhosis and in the management.

Urinary tract infections (UTI) (23-41\%) and spontaneous bacterial peritonitis (SBP) (20-35\%) are the most common infections in cirrhotic patients; pneumonia (8-14\%), spontaneous bacteraemia $(8-21 \%)$, and skin and soft tissues infections (SSTIs, 6-13\%), though less frequent, may cause significant and can prove fatal.

Epidemiology of liver infections varies globally. ${ }^{9,10}$ Data on BI in liver cirrhosis in Indian patients is limited. Aim of the study was to explore the epidemiological pattern of BI in hospitalized adult Indian patients with cirrhosis of liver with determination of the causative agents. Objective of this study was evaluation of therapeutic/empirical approaches for infections as the objectives.

\section{METHODS}

This prospective observational study was carried out by the department of Pharmacy practice of a pharmacy college and pharmacology of a tertiary care teaching hospital, during October 2018 to March 2019, after obtaining the approval from the Institutional Ethics Committee, prospective participants were screened after obtaining a written informed consent.

Patients aged above 25 years, who were diagnosed with BI with chronic liver disease/cirrhosis with features of portal hypertension, ascites, variceal bleeding, hepatic encephalopathy, hepato-renal syndrome, type 2 diabetes mellitus, alcohol abuse, metabolic syndrome were included. Patients with auto-immune liver disease, inherited liver disorders, drug-induced liver disease, hepato-cellular carcinoma, hepatic injury caused by viral, fungal, and protozoan infection, haemolytic anaemia, pregnant and lactating women, heart failure, acute poisoning were excluded.

Details of relevant medical history, clinical and laboratory investigations, treatment history were obtained from the case records, treatment charts and prescriptions. Inputs from the body fluid analysis and culture reports for the identification of causative organisms and type of bacterial involved in the infection were recorded. CTP was used to assess the severity of the liver disease. Antibiotic treatment strategy was analyzed to document antibiotic prescribed for the corresponding infections. Prescribed antibiotics were checked for contraindications using the Lexicomp software.

\section{Statistical analysis}

Data was captured on Microsoft excel worksheets and edited for completeness. Descriptive statistics (frequency, percentage) was used; tables and figures were used as appropriate. Chi-square test was used to determine the association between BI and liver cirrhosis.

\section{RESULTS}

Data of 60 cirrhotic patients with infections, meeting the selection criteria were available for analysis. There were $50(83.3 \%)$ males and $10(16.6 \%)$ females $(\mathrm{p}=0.082)$.

The mean age \pm SD was $50.5 \pm 3.77$ years. Twenty-eight (46.66\%, female- $01,3.57 \%$ ) were alcoholics, four (6.66\%, all males) were both alcoholic and smokers; twenty-eight $(46.66 \%$, males- $19,67.86 \%$, females- 09, $32.14 \%$ ) were neither smokers nor alcoholics. There were $31(62 \%)$ male patients who smoked tobacco and consumed alcohol but only one female patient (10\%) was alcoholic.

The mean age of the patients was 50.5 years \pm 3.77 , higher for females (62 years \pm 5.73$)$. There were $41(68.33 \%)$ patients aged $>50$ years $(\mathrm{p}=0.910)$ (Table 1$)$.

Thirty-six (60\%) patients had co-existing illnesses, 23 $(76.66 \%)$ with multiple co-morbidities; 13 (36.11\%) patients had single co-existing illness, type 2 diabetes mellitus $(n=09,18 \%)$ and hypertension $(n=04,6.66 \%)$ (Table 2). Maximum number of co-morbidities was four. Diabetes mellitus and hypertension were the common comorbidities. More number of males had associated comorbidities attributable to more number of male patients in this study. Type 2 diabetes mellitus is an independent factor of poor prognosis, a risk factor for increased complications and infections in particular.

\section{Types of infection}

SPB $(n=22,36.6 \%)$ and UTI $(n=18,30)$ we are the common infections, with E. coli, K. pneumoniae being the common isolates. Table 3 lists the infections and the common causative organisms that caused BI in our study population.

\section{Causative organisms}

There were 35 culture positives. E. coli $(10,28.5 \%)$ was the most common causative organism. The other predominant organisms involved in the infection were $K$. pneumonia $(\mathrm{n}=05,14.2 \%)$, Enterococcus spp $(\mathrm{n}=04$, $11.4 \%), K$. oxytoca, Coagulase-negative staphylococci and $S$. aureus were isolated from three $(8.5 \%)$ each, gram positive cocci $(\mathrm{n}=02,5.7 \%)$ and Citrobacter ferendii, gram-negative cocci, $P$. aeruginosa, S. hemolyticus, $\beta$ hemolytic streptococcus spp. isolated from one each. 


\section{CTP score}

CTP score was calculated for all patients to predict the survival rate; thirty-six $(60 \%)$ patients were in class $\mathrm{C}$ indicating one-year survival rate of $45 \%$. Those in class B $(19,31.66 \%)$ and $\mathrm{A}(05,8.3 \%)$ were less $(\mathrm{p}=0.0 .630)$ (Table 4).

\section{Antibiotic therapy in cirrhotic patients}

Eleven different classes of antibiotics are prescribed to treat infections. Majority of the patients were treated with $>1$ class of antibiotic during hospitalization. The minimum duration of therapy with each antibiotic in a patient was about 3 days (range 3-7 days).
Cephalosporins $(37,61.7 \%)$, other antibiotics (rifaximin) $(31,51.7 \%)$, penicillin+ß-lactamase inhibitors $(22$, $36.7 \%)$, carbapenems $(8,13.3 \%)$, fluoroquinolones $(6$, $10 \%)$; three patients each received imidazole, lincomycin, oxazolidinone and one patient each received nitrofurans, glycopeptide inhibitors, macrolides.

None of the antibiotics prescribed in our study were contraindicated but certain drugs such as metronidazole, lincomycin and ceftriaxone had an advice to use with caution in patients with hepatic impairment. In our study they were absolutely indicated, and when prescribed, patients were monitored for any possible adverse effects.

Table 1: Age wise distribution of study population.

\begin{tabular}{|lllllll|}
\hline Age (years) & $\begin{array}{l}\text { Total } \\
\text { N }(\boldsymbol{\%})\end{array}$ & $\begin{array}{l}\text { Mean age } \\
\text { (years) } \mathbf{S D}\end{array}$ & $\mathbf{N}(\boldsymbol{\%})$ & $\begin{array}{l}\text { Mean age } \\
\text { (years) } \pm \text { SD }\end{array}$ & $\mathbf{N}(\boldsymbol{\%})$ & $\begin{array}{l}\text { Mean age } \\
\text { (years) } \pm \text { SD }\end{array}$ \\
\hline$<\mathbf{4 0}$ & $6(10)$ & $35 \pm 1.77$ & 06 & $35 \pm 1.77$ & 0 & 0 \\
\hline $\mathbf{4 0 - 5 0}$ & $10(16.6)$ & $45 \pm 3.52$ & 10 & $45 \pm 3.52$ & 0 & 0 \\
\hline $\mathbf{5 1 - 6 0}$ & $23(38.3)$ & $53 \pm 2.55$ & 19 & $54 \pm 3.04$ & 04 & $52 \pm 2.06$ \\
\hline$>\mathbf{6 0}$ & $21(35)$ & $69 \pm 7.23$ & 15 & $66 \pm 5.07$ & 06 & $72 \pm 9.39$ \\
\hline Total & 60 & $50.5 \pm 3.77$ & 50 & $50 \pm 3.35$ & 10 & $62 \pm 5.73$ \\
\hline
\end{tabular}

Table 2: Comorbidities in the study population.

\begin{tabular}{|c|c|c|c|}
\hline \multirow{2}{*}{ Parameter } & \multicolumn{2}{|c|}{ Gender $\mathbf{N}(\%)$} & \multirow[t]{2}{*}{ P value } \\
\hline & Male & Female & \\
\hline Type 2 diabetes mellitus & $9(15)$ & 0 & 0.076 \\
\hline Hypertension & $4(6.66)$ & 0 & 0.179 \\
\hline Hypertension and type 2 diabetes mellitus & $7(11.6)$ & $2(3.33)$ & 0.315 \\
\hline Hypertension, type 2 diabetes mellitus, hypoglycaemia & $1(1.66)$ & 0 & 0.327 \\
\hline $\begin{array}{l}\text { Hypertension, type } 2 \text { diabetes mellitus, chronic kidney disease and } \\
\text { pulmonary edema }\end{array}$ & 0 & $1(1.66)$ & $0.014 *$ \\
\hline Type 2 diabetes mellitus, ischemic heart disease, acute kidney injury & 0 & $1(1.66)$ & $0.014 *$ \\
\hline Ischemic heart disease, hypertension, vericose veins with eczema & $1(1.66)$ & 0 & 0.327 \\
\hline $\begin{array}{l}\text { Hypertension, type } 2 \text { diabetes mellitus, diabetic kidney disease, old } \\
\text { cerebrovascular accident }\end{array}$ & 1 1.66) & 0 & 0.327 \\
\hline Hypertension, type 2 diabetes mellitus, cholelithiasis & $1(1.66)$ & 0 & 0.327 \\
\hline Hepatic dysfunction & $1(1.66)$ & 0 & 0.327 \\
\hline Grade 2 haemorrhoids & $1(1.66)$ & 0 & 0.327 \\
\hline Alcohol dependence syndrome, lumbar spondylosis & $1(1.66)$ & 0 & 0.327 \\
\hline $\begin{array}{l}\text { Alcohol withdrawal syndrome with withdrawal seizures, } \\
\text { hypertension, ischemic heart disease, anaemia }\end{array}$ & $1(1.66)$ & 0 & 0.327 \\
\hline $\begin{array}{l}\text { Coronary artery disease. myocardial infarction, type } 2 \text { diabetes } \\
\text { mellitus }\end{array}$ & $1(1.66)$ & 0 & 0.327 \\
\hline Multiple episodes of renal calculi & $1(1.66)$ & 0 & 0.327 \\
\hline Undergone surgery for gastric ulcer and hernia & $1(1.66)$ & 0 & 0.327 \\
\hline Urinary tract infection, type 2 diabetes mellitus & 0 & $1(1.66)$ & $0.014 *$ \\
\hline Total & $31(51.66)$ & $05(8.33)$ & \\
\hline No comorbidities & $19(31.66)$ & $5(8.33)$ & 0.241 \\
\hline
\end{tabular}

*statistically significant 
Table 3: Bacterial infections in the study population.

\begin{tabular}{|c|c|c|}
\hline Type of infection & $\mathbf{N}(\%)$ & Isolates \\
\hline $\begin{array}{l}\text { Spontaneous bacterial peritonitis } \\
\text { (SBP) }\end{array}$ & $22(36.6)$ & E coli, K. pneumonia, Enterococcus faecalis. \\
\hline Urinary tract infection & $18(30)$ & $\begin{array}{l}\text { E. coli, K. pneumonia, K. oxytoca, Citrobacter ferendii, } \\
\text { Enterococcus aerogenus, Staph aureus }\end{array}$ \\
\hline Respiratory tract infection & $09(15)$ & $\begin{array}{l}\text { E. coli, K. pneumonia, Enterococcus faecalis, Staph aureus, } \\
\text { Coagulase negative staphylococci, } \beta \text {-hemolytic streptococcus } \\
\text { spp, gram-positive and gram-negative cocci }\end{array}$ \\
\hline Sepsis & $08(13.3)$ & $\begin{array}{l}\text { Staphy hemolyticus, } \\
\text { P. aeruginosa, K. pneumonia, Coagulase negative } \\
\text { staphylococci }\end{array}$ \\
\hline Cellulitis & $02(3.3)$ & K. pneumonia, Coagulase negative staphylococci \\
\hline Acute gastroenteritis & $01(1.6)$ & \\
\hline
\end{tabular}

Table 4: Comparison of risk category in different age groups and gender.

\begin{tabular}{|c|c|c|c|c|c|c|c|}
\hline \multirow{3}{*}{$\begin{array}{l}\text { Age group } \\
\text { (years) }\end{array}$} & \multicolumn{6}{|c|}{ Risk category } & \multirow{3}{*}{ Total } \\
\hline & \multicolumn{2}{|l|}{$\mathbf{A}$} & \multicolumn{2}{|c|}{ B } & \multicolumn{2}{|l|}{ C } & \\
\hline & Male & Female & Male & Female & Male & Female & \\
\hline$<40$ & 0 & 0 & 01 & 0 & 05 & 0 & 06 \\
\hline $40-50$ & 0 & 0 & 04 & 0 & 06 & 0 & 10 \\
\hline $51-60$ & 01 & 0 & 07 & 0 & 11 & 04 & 23 \\
\hline$>60$ & 03 & 01 & 05 & 02 & 07 & 03 & 21 \\
\hline Total & 04 & 01 & 17 & 02 & 29 & 07 & 60 \\
\hline
\end{tabular}

\section{DISCUSSION}

BI is common in patients with liver cirrhosis due to compromised immune status, altered gut status resulting in increased permeability and gut bacteria. ${ }^{1}$ Hospitalization, further doubles the chances of infection in these patients. For this reason, we selected hospitalized cirrhotic patients with BI as our study cohort.

There is a male predominance $(83 \%)$ in our study, which is well documented in literature. ${ }^{6,11-12}$ Our patients were younger by a decade as previous reports stated a higher mean age $(64.5 \pm 12.2$ years and $61 \pm 13$ years $) .{ }^{11-12}$ The patients in the age group of $>50$ years $(44 \%)$ were the most vulnerable subgroup in our study, comparable with that reported by Yuan et al $(55.7 \pm 13.3$ years $)$ and Andreu et al $(64 \pm 13$ years $) .{ }^{13,14}$ In our study, all females were aged $>51$ years. Because of cultural and traditional values in this subcontinent, females do not indulge in alcoholism which is comparable with the study of Amin et al. ${ }^{15}$

Our study supports the presence of multiple co-morbidities as a common occurrence among cirrhotic patients; $3 / 5$ th $(60 \%)$ of our patients had co-existing illnesses, and $76.66 \%$ had multiple co-morbidities; type 2 diabetes mellitus (18\%) and hypertension $(6.66 \%)$ were the most common co-morbidities. Maximum number of comorbidities in our study cohort was four. More number of males had associated co-morbidities attributable to male preponderance. Type 2 diabetes mellitus is an independent factor of poor prognosis also a risk factor for increased complications and infections in particular.

UTI, SBP, Pneumonia, SSTI are the most common BI among cirrhotic patients. ${ }^{5,16-19}$ The mortality rate of patients with SBP ranges from $10-50 \% .{ }^{20}$ Patients who survive the first episode of SBP have a $70 \%$ chance of recurrent infection. The first choice of antibiotics in treating SBP is third generation cephalosporins. Due to increased risk of nephrotoxicity, the drugs combined with aminoglycoside antibiotics are not used. ${ }^{21}$ SBP (36.6\%) was the most common type of infection in our study population, probably due to a contagion of pre-existing ascites by bacterial organisms of intestinal provenance which is supported by Conn et al. ${ }^{22}$ Delay in antibiotic therapy increases the mortality during hospitalization (10$50 \%)$ and one-year mortality rate $(31-93 \%){ }^{23}$

Urinary tract infections, the second common infections (20-40\%), more common among women, with gram negative organisms (E. coli) as causative organism; pneumonia is the third most common infections (15-21\%) in cirrhosis with a high mortality rate of $37-41 \%$ (8). ${ }^{2,5,16,24,25}$

Skin and soft tissue infection (SSTI) is seen in $2-11 \%$ of cirrhotic patients especially male alcoholics. ${ }^{26}$ They are often recurrent, caused by gram positive and in few occasions translocated by gram-negative bacteria. Though mortality rate is comparatively less $(20 \%)$, it has a potential to cause renal failure and hence, may increase the mortality. Cellulitis and erysipelas are the skin infections 
that progress as a the result of bacterial entry through the skin barrier and lymphangitis of the lower terminus and the walls of the abdomen are the frequent soft tissue infections in cirrhotic patients. ${ }^{27}$ Acute gastroenteritis (GE) occurs rarely in cirrhotic patient and the common organisms involved in the infection are E. coli, gram-negative fermenter bacilli and fungi. Other uncommon infections due to cirrhosis are endocarditis and meningitis.

Infections caused by extended-spectrum $\beta$-lactamaseproducing enterobacteriaceae (ESBL-E), methicillinresistant staphylococcus aureus (MRSA) and enterococcus faecium are increasing in patients with cirrhosis, accounting to $34 \%$ of hospitalized patients, globally. ${ }^{28}$ Acinetobacter baumanni, Clostridium difficile were not reported in our study. Gram negative bacilli are increasingly being common causative organisms. Infections reported in our study are in similar to the previous reports. ${ }^{18,29}$

There were 35 culture positives in our study. E. coli $(28.5 \%)$ was the most common causative organism similar to the previous reports. ${ }^{2,14,20,30}$ Peveden report culture positivity in $20.91 \%$ patients; gram negative bacteria, $E$. coli $(71.87 \%)$ was the common isolate. ${ }^{5} E$. coli belongs to the phylum proteobacteria and is one of the predominant groups residing in the intestine. Due to dysbiosis and bacterial translocation caused by cirrhosis resulted in the $E$. coli being the more commonly isolated organism. The other predominant organisms in our patietns were $K$. pneumonia, Enterococcus spp, K. oxytoca, Coagulasenegative staphylococci and $S$. aureus. Results of our study are reflective of trend indicated by a global study. ${ }^{20}$

Piano et al have reported E. coli (28\%), K. pnemononiae (14\%), enterococci $(12 \%)$, S. aureus $(8 \%)$ as common causative organisms. ${ }^{28} P$. aeruginosa $(3 \%)$, other gram positive (18\%) and other gram-negative organisms (15\%) contributed to the pool of infections.

There were nine cases $(15 \%)$ of lower respiratory tract infections (LRTI) in our study which is comparable with Amin et al which had 12 cases of LRTI. In a previous study by Andreu et al no organisms were isolated from the respiratory tract. ${ }^{14,15}$

Eight cases (13\%) of sepsis were identified in our study of whom $50 \%$ were culture-positive; in the remaining $50 \%$, the diagnosis was ruled out based on the criteria of clinical signs and symptoms of the patients.

Cellulitis and erysipelas are the skin infections that progress due to the result of bacterial entry through the skin barrier and lymphangitis of the lower terminus and the walls of the abdomen are the frequent soft tissue infections in cirrhotic patients. Cellulitis was the most commonly reported dermatological infections observed in our study which is supported by Naqvi et al. ${ }^{30}$ To date, there is only very few studies have assessed the risk factors for cellulitis. It was assumed that hepatic encephalopathy, hypoalbuminemia, and high CTP score play a vital role in the development of cellulitis in cirrhotic patients.

Acute GE is rare in cirrhotic patients with infections. In our study one case $(1.6 \%)$ of acute GE was identified which was culture-negative.

CTP score was calculated for all patients to predict the survival rate; thirty-six $(60 \%)$ patients were in class $\mathrm{C}$ indicating one-year survival rate of $45 \%$. Those in class $\mathrm{B}$ $(31.66 \%)$ and $\mathrm{A}(8.3 \%)$ were less. In contrast, Gomes et al have noted that $42.7 \%$ were in stage $\mathrm{B}$, stage $\mathrm{C}(39.3 \%)$ and stage A (18\%) were less frequent. ${ }^{11}$

Initial empiric antibiotic therapy consisting of broadspectrum agents, later isolate adjusted therapy is followed routinely in the clinical practice globally and so in our hospital. It is crucial that empiric antibiotic therapy started at the earliest, to prevent the mortality in the first six hours of hospitalization.

The patients were advised to complete the course of an antibiotic which was prescribed during the time of hospitalization, even when the culture reports were negative, to prevent bacterial resistance. There were few severe infections where patients needed to be treated with an antibiotic(s) more than the recommended duration of therapy. Third generation cephalosporins are frequently used because they have a low risk of adverse events of superinfection and antibiotic-induced renal toxicity which is supported by Ghassemi et al. ${ }^{21}$

While prescribing antibiotic therapy, the physician has to be aware of the local epidemiology common causative organisms prevailing, severity and type of infection; safety of antimicrobials in cirrhosis, possible drug interactions, pharmacokinetics and pharmacodynamics of the agent, and its safety has to be considered and monitored. ${ }^{9}$ It is noteworthy to remember that multidrug resistance is high globally (34\%), being highest in Asia and India in particular, which is an additional reason for the use of appropriate antibiotic therapy to minimize treatment failure. ${ }^{28}$

\section{CONCLUSION}

Bacterial infections are common among cirrhotic patients. SPB and UTI are the common infections, with E. coli, $K$. pneumoniae being the common isolates. The risk of bacterial infections is high depending upon the severity of liver damage.

The choice of a particular antibiotic depends on the type of causative organism involved in the infection. To reduce the risk of drug induced hepato-toxicity, for better clinical outcomes, use of appropriate antibiotic therapy with dose adjustments and individualizing the dosage has to be considered. 


\section{ACKNOWLEDGEMENTS}

Authors would like to thank and acknowledge the support of Dr. M S Latha for her assistance.

Funding: No funding sources

Conflict of interest: None declared

Ethical approval: The study was approved by the Institutional Ethics Committee

\section{REFERENCES}

1. Bruns T, Zimmermann HW, Stallmach A. Risk factors and outcome of bacterial infections in cirrhosis. World J Gastroenterol. 2014;20(10):2542-54.

2. Borzio M, Salerno F, Piantoni L, Cazzaniga M, Angeli $\mathrm{P}$, Bissoli F, et al. Bacterial infection in patients with advanced cirrhosis: a multicentre prospective study. Dig Liver Dis. 2001;33(1):41-8.

3. Fernandez J, Navasa M, Gomez J, Colmenero J, Vila J, Arroyo V, et al. Bacterial infections in cirrhosis: epidemiological changes with invasive procedures and norfloxacin prophylaxis. Hepatology. 2002;35(1):140-8.

4. Fernandez J, Acevedo J, Castro M, Garcia O, Lope CR, Roca D, Pavesi M, et al. Prevalence and risk factors of infections by multiresistant bacteria in cirrhosis: a prospective study. Hepatology. 2012;55(5):1551-61.

5. Preveden T. Bacterial infections in patients with liver cirrhosis. Med Pregl. 2015;68(5):187-91.

6. Bajaj JS, Leary JG, Reddy KR, Wong F, Biggins SW, Patton H, Fallon MB, et al. Survival in infectionrelated acute-on-chronic liver failure is defined by extrahepatic organ failures. Hepatology. 2014;60(1):250-6.

7. Moreau R, Jalan R, Gines P, Pavesi M, Angeli P, Cordoba $\mathrm{J}$, et al. Acute-on-chronic liver failure is a distinct syndrome that develops in patients with acute decompensation of cirrhosis. Gastroenterology. 2013;144(7):1426-37.

8. Allaire M, Cadranel JF, Nguyen TTN, Garioud A, Zougmore $\mathrm{H}$, Heng R, et al. Management of infections in patients with cirrhosis in the context of increasing therapeutic resistance: A systematic review. Clin Res Hepatol Gastroenterol. 2020;44(3):264-74.

9. Piano S, Angeli P. Current Concepts on Bacterial and Fungal Infections in Cirrhosis. Clin Liver Dis. 2019;14(3):87-91.

10. Jalan R, Fernandez J, Wiest R, Schnabl B, Moreau R, Angeli P, Stadlbauer V, et al. Bacterial infections in cirrhosis: a position statement based on the EASL Special Conference 2013. J Hepatol. 2014;60(6):1310-24.

11. Lameirao GC, Violante SR, Carrola P, Presa J. Bacterial Infections in Patients with Liver Cirrhosis in an Internal Medicine Department. GE Port J Gastroenterol. 2019;26(5):324-32.

12. Lagadinou M, Gogos CA. Bacterial infections in cirrhosis patients: a retrospective epidemiologic study in a greek university hospital. Clinical Hepatol and Hepatitis reports. 2015;2:1.

13. Yuan LT, Chuah SK, Yang SC, Liang CM, Wu CK, Tai WC, et al. Multiple bacterial infections increase the risk of hepatic encephalopathy in patients with cirrhosis. PLoS One. 2018;13(5):197127.

14. Andreu M, Sola R, Stiges SA, Alia C, Gallen M, Vila $\mathrm{MC}$, et al. Risk factors for spontaneous bacterial peritonitis in cirrhotic patients with ascites. Gastroenterol. 1993;104(4):1133-8.

15. Amin H, Sabry AMM, Ahmed RE, Makhlouf NA. Types and microbiological spectrum of infections in patients with cirrhosis: A single-centre experience in Upper Egypt. Arab J Gastroenterol. 2017;18(3):159-64.

16. Fasolato S, Angeli P, Dallagnese L, Maresio G, Zola E, Mazza E, et al. Renal failure and bacterial infections in patients with cirrhosis: epidemiology and clinical features. Hepatology. 2007;45(1):223-9.

17. Angeli P. Bacterial infections complicating Cirrhosis. Paris Hepatitis Conference, 2018. Available at: https://www.aphc.info/wpcontent/uploads/2018/01/p hc-2018-def.pdf. Accessed on 11 October 2020.

18. Ekpanyapong S, Reddy KR. Infections in Cirrhosis. Curr Treat Options Gastroenterol. 2019;17(2):254-70.

19. Piano S, Singh V, Caraceni P, Maiwall R, Alessandria $\mathrm{C}$, Fernandez J, et al. Epidemiology, predictors and outcomes of multi drug resistant (MDR) bacterial infections in patients with cirrhosis across the world. Digestive and Liver Disease. 2018;50(1):2-3.

20. Anastasiou J, Williams R. When to use antibiotics in the cirrhotic patient? The evidence base. Ann Gastroenterol. 2013;26(2):128-31.

21. Ghassemi S, Garcia T G. Prevention and treatment of infections in patients with cirrhosis. Best Pract Res Clin Gastroenterol. 2007;21(1):77-93.

22. Conn HO, Fessel JM. Spontaneous bacterial peritonitis in cirrhosis: variations on a theme. Medicine. 1971;50(3)161-97.

23. Wiest R, Krag A, Gerbes A. Spontaneous bacterial peritonitis: recent guidelines and beyond. Gut. 2012;61(2):297-310.

24. Zsuzsanna Vitalis, Maria Papp. In: Blackwell RM, Tyson AP. Bacterial Infections in Cirrhosis. Hungary: Nova Science Publishers; 2014: 1-26.

25. Gustot T, Durand F, Lebrec D, Vincent JL, Moreau R. Severe sepsis in cirrhosis. Hepatology. 2009;50(6):2022-33.

26. Mohan P, Ramu B, Bhaskar E, Venkataraman J. Prevalence and risk factors for bacterial skin infection and mortality in cirrhosis. Ann Hepatol. 2011;10(1):15-20.

27. Nouh MA, Basha MA, Deeb GS, Masoud BM, Hammouda HA. Skin and soft tissue bacterial infections in cirrhotic patients with edema. Menoufia Med J. 2016;29(2):454-9.

28. Piano S, Singh V, Caraceni P, Maiwall R, Alessandria C, Fernandez J, Soares EC, et al. Epidemiology and Effects of Bacterial Infections in Patients With 
Cirrhosis Worldwide. Gastroenterology. 2019;156(5):1368-80.

29. Cassard AM, Ciocan D. Microbiota, a key player in alcoholic liver disease. Clin Mol Hepatol. 2018;24(2):100-7.

30. Naqvi IH, Mahmood K, Talib A, Ubaid M, Mahmood A. Infections in Cirrhotics: Types, Microbiological
Spectrum and Risk Factor- 5-Year Cohort Study. Open J of Gastroenterol. 2014;4(3):105-17.

Cite this article as: Gopinath $\mathrm{DC}$, Bhat R, Sivichan S, Sharon MS, Jose S, Ranjan A, et al. Bacterial infections in Indian cirrhotic patients: a prospective study. Int J Basic Clin Pharmacol 2021;10:668-74. 